\section{Complications Associated with Pedicle Screw Placement Using Cortical Bone Trajectory}

\section{Abstract}

Pedicle screw placement using cortical bone trajectory has become a popular method of fixation especially in minimal invasive spine surgery over the last few years. Complications of this technique have been rarely reported in the literature. A clear understanding of fractures and screw loosening is crucial before embarking on this new surgical technique. Fatigue failure in osteoporotic bone using this technique is alarming and warrants further study to understand its indication.

Received: September 21, 2015; Accepted: September 23, 2015; Published: September 28, 2015

\section{Introduction}

Cortical bone trajectory (CBT) technique for pedicle screw placement in the lumbar spine has described first by Santoni in 2009 [1]. The advantages of using CBT technique involve increased screw purchase within cortical bone and reduced surgical dissection when compared to the traditional pedicle screw (Figure 1) [2-4]. These factors make CBT technique an attractive alternative to standard pedicle screw fixation. This technique is particularly attractive in patients who have compromised bone quality. Several biomechanical studies $[1,5-10]$ were able to demonstrate comparable pull out and toggle strength between CBT and traditional pedicle screw technique. In contrary to these favourable biomechanical results, there is limited data on complications of CBT. In one study Glennie et al. [11] reported screw loosening in 5 of 8 patients. Following are some of the complication we have encountered over the last four years when placing pedicle screws using the CBT.

Pars/pedicle Fractures: In our clinical series, we experienced pars/ pedicle fracture with CBT during both intraoperative as well as postoperative period. The fracture started at the entry point, which was medial to the lateral pars; continued through the superior facet then exited out to the lateral aspect of pedicle. We were able to duplicate this identical fracture during our cadaveric study. (Figure 2)

Screw Loosening: Four out of the initial 26 patients demonstrated radiographic lucency surrounding pedicle screws within 3 month

\section{Yusuf T. Akpolat, 'Olumide A. Danisa and 'Wayne K. Cheng}

\author{
Department of Orthopaedic Surgery, Loma \\ Linda University, CANADA
}

Corresponding Author: Wayne K. Cheng

Department of Orthopaedic Surgery, Loma Linda University, CANADA.

”md4spine@yahoo.com

Tel: (909) 558-6444

Fax: (909) 558-6118

Citation: Akpolat YT, Danisa OA, Cheng WK. Complications Associated with Pedicle Screw Placement Using Cortical Bone Trajectory. J Clin Exp Orthop. 2015, 1:1.

after their initial surgery. This was clearly demonstrated on their CT myelograms, which raised concerns of pseudo arthritis (Figure 3). In addition to our clinical experience, biomechanical studies were performed in our lab to compare fatigue strength of CBT to traditional pedicle screw using osteoporotic cadavers. Side by side comparisons were performed on 12 cadaveric vertebrae. Pedicle screws placed using traditional trajectory outperformed screws placed using cortical bone trajectory based on fatigue testing in osteoporotic vertebrae. CBT screws reached relative motion of 15.2 degree (SD: 5.5), while traditional pedicle screw's relative motion was 6.9 degree (SD: 4.8) after 100 cycle with 4 $\mathrm{Nm}$ load. Pedicle screw placement using cortical bone trajectory has become a popular method of fixation especially in minimal invasive spine surgery over the last few years. Complications of this technique have been rarely reported in the literature. A clear understanding of fractures and screw loosening is crucial before embarking on this new surgical technique. Fatigue failure in osteoporotic bone using this technique is alarming and warrants further study to understand its indication. 


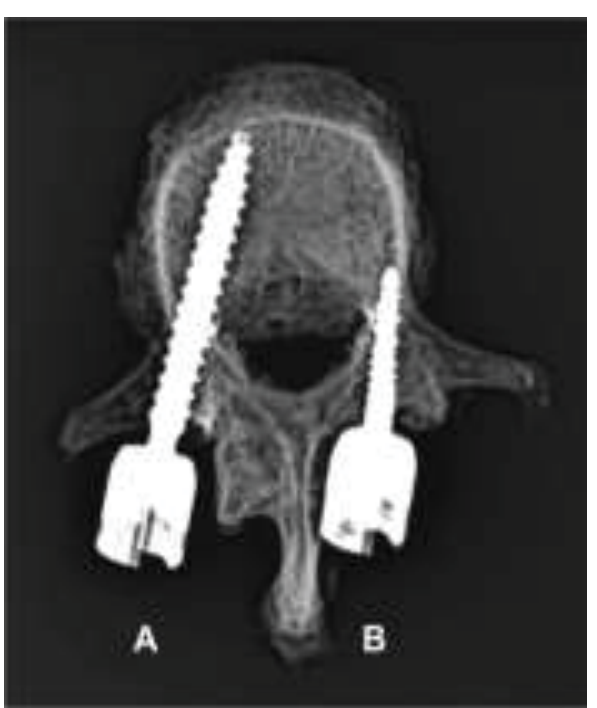

Figure 1
Traditional pedicle screw (A) vs. Cortical Bone Trajectory Screw (B).

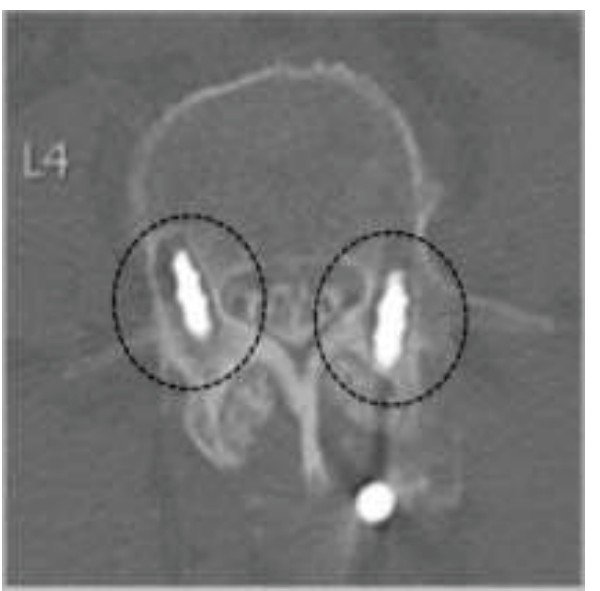

Figure 3 Lucency around cortical bone trajectory pedicle screws indicating screw loosening..

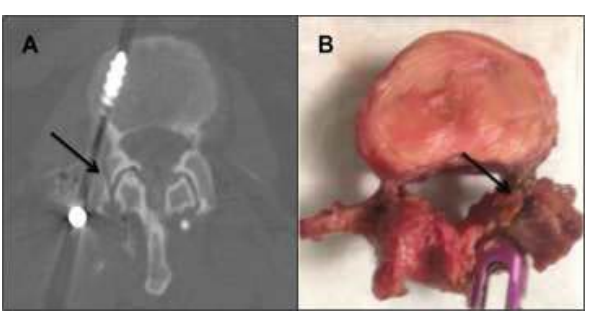

Figure 2 Figure A showing pars/pedicle fracture on immediate post-op CT scan. Fracture had occurred intra-operatively while using CBT. Screw placed with $\mathrm{CBC}$ was removed and replaced with pedicle screw using traditional trajectory. Figure B showing fracture on human cadaveric vertebra. The fracture started at the screw insertion point on the lateral border of the pars, extended in a semi-sagittal oblique plane through the medial aspect of the superior facet, continued through the pedicle, then exited out the lateral aspect of the pedicle. 


\section{References}

1 Santoni B.G, Hynes RA, McGilvray KC, Rodriguez-Canessa G, Lyons AS, et al. (2009) Cortical bone trajectory for lumbar pedicle screws. Spine J 9: 366-373.

2 Lee G.W, Son JH, Ahn MW, Kim HJ, Yeom JS, et al. (2015) The Comparison of Pedicle Screw and Cortical Screw in Posterior Lumbar Inter-body Fusion: a Prospective Randomized Non-inferiority Trial. Spine J 15: 1519-1526.

3 Pacione D, Kim I, Wilson TA, Frempong-Boadu A (2015) Cortical screw trajectory for instrumentation and fusion in the setting of osteopathic compression fracture allows for percutaneous kyphoplasty for adjacent level compression fractures. J Clin Neurosci 22: 899-904.

4 Takata Y, Matsuura T, Higashino K, Sakai T, Mishiro T, et al. (2014) Hybrid technique of cortical bone trajectory and pedicle screwing for minimally invasive spine reconstruction surgery: a technical note. $J$ Med Invest 61: 388-392.

5 Perez-Orribo L, Kalb S, Reyes PM, Chang SW, Crawford NR, et al. (2013) Biomechanics of lumbar cortical screw-rod fixation versus pedicle screw-rod fixation with and without interbody support. Spine (Phila Pa 1976) 38: 635-641.
6 Baluch D.A, Patel AA, Lullo B, Havey RM, Voronov LI, et al. (2014) Effect of Physiologic Loads on Cortical and Traditional Pedicle Screw Fixation. Spine 39: E1297-1302.

7 Matsukawa K, Yato Y, Kato T, Imabayashi H, Asazuma T, et al. (2014) In vivo analysis of insertional torque during pedicle screwing using cortical bone trajectory technique. Spine (Phila Pa 1976) 39: E240245.

8 Inceoglu S, Montgomery WH Jr, St Clair S, McLain RF (2011) Pedicle screw insertion angle and pull out strength: comparison of 2 proposed strategies. J Neurosurg Spine 14: p. 670-676.

9 Calvert G.C, Lawrence BD, Abtahi AM, Bachus KN, Brodke DS, et al. (2015) Cortical screws used to rescue failed lumbar pedicle screw construct: a biomechanical analysis. J Neurosurg Spine 22: 166-172.

10 Wray S, Mimran R, Vadapalli S, Shetye SS, McGilvray KC, et al. (2015) Pedicle screw placement in the lumbar spine: effect of trajectory and screw design on acute biomechanical purchase. J Neurosurg Spine 22: 503-510.

11 Andrew Glennie R, Dea N, Kwon BK, Street JT (2015) Early clinical results with cortically based pedicle screw trajectory for fusion of the degenerative lumbar spine. J Clin Neurosci 22: 972-975. 